lying soil and rock and enters living areas by diffusion, convection and ventilation. Radon-222 decays through several alpha and beta decays into various radioactive isotopes of polonium, bismuth and lead. Radon progeny are usually charged positive ions which readily attach to dust and aerosol particles in the air. These charged clusters can drift in the high electric fields surrounding the faces and bezels of computer video display terminals (VDT) and television sets. This electrostatic pumping action can collect and concentrate the radioactive radon progeny from a very large volume of air surrounding the viewing screen resulting in a high level of radioactivity on the glass faceplate and surrounding bezel. The electrostatic pump is continuously being fed by convection and ventilation air currents in the room collecting the radon progeny from large air volumes. Rough calculations indicate that as many as $10^{7}$ radioactive progeny can be collected per $100 \mathrm{~cm}^{2}$ of screen area before the screen is fully discharged. Measurements using a common VDT verify that these total integrated activities were achieved in several experimental runs. Television sets and VDTs in normal use always show alpha activities well above background activities of other objects in the nearby environment (table surfaces, walls, metal plates, glass plates). The maximum activities on television sets and VDTs occur shortly after they are turned off. When turned off, the face falls to a large negative voltage and becomes an efficient collector of positive ions. This pumping action can continue for many hours if the air is dry and the main source of air ionization is from the radon background.

Measurements were carried out in various rooms of our one-storey building

\section{New image}

SIR - Daedalus has hit the mark again in his article about light-pulse imaging of body tissues (Nature 348, 290: 1990). Measurement of the transmitted ray does provide imaging of body tissues (Photon Migration in Tissues, ed. B. Chance: Plenum, 1989). The technique works for small objects such as fingers, hands and small animals and, with difficulty, for mammography.

The difficulty is that the early component of the light pulse that takes a direct path constitutes a smaller and smaller fraction of the light as one goes from fingers to arms to heads to chests. In this case more people are interested in what is termed 'photon migration": a random walk process (Lord Rayleigh Phil. Mag. 37. 321: 1919). If larger objects are to be probed. for example the head. heart and liver, it is clear that quite different rules of light travel will be applied to photons which migrate from the input position to in Santa Clara, California. The radon levels in different rooms were measured with a Honeywell At-Ease radon monitor which displays the current radon level (last 12 hours) and the average level (average since last reset) in units of picocuries per litre. The monitor has indicated current levels between 0.9 and 3.9 with an average of 1.7 over 90 days. The alpha activity was measured with a $40-\mathrm{cm}^{2}$ silicon semiconductor alpha detector followed by the usual charge amplifier, shaping amplifier, threshold discriminator (3-MeV threshold) and electronic counter. The system energy calibration was determined using a plated Am-241 alpha source $(5.78 \mathrm{MeV})$. The detector is taped to various locations on the glass faceplate and/or bezel for activity measurements. The data are normalized to $100 \mathrm{~cm}^{2}$ and $4 \pi$ geometry as recommended for reporting surface activities. Measurements were made on several types of common microcomputer VDTs and colour television sets. Colour monitors show the highest levels of activities, which is expected as these monitors use the highest voltages in the cathode ray tubes. Alpha activities generally increase with the current radon concentration but are highly variable on a day-to-day basis. The highest level observed to date was $9,000 \alpha$-d.p.m. 100 $\mathrm{cm}^{-2}$ measured on a colour computer VDT operated in a closed front office. The radon level was not measured in the room, but the radon level in the more open part of the building was at $3.9 \mathrm{pCil}^{-1}$ at the time of the measurements.

\section{Quantrad Sensor Division,}

F.P. ZIEMBA

Applied Electron Corporation,

2360 Owen Street,

Santa Clara,

California 95054, USA

the output position along optical paths that are 5-10 times longer than the direct path. The advantages of this photonmigration technique is that many photons travel these devious pathways. Luckily, they migrate in random walk patterns with a rather good mean directionality: the random walk pattern is highly sensitive to the presence of absorbing objects. In fact. migrating photons allow us for the first time to see behind absorbing objects. Many algorithms for image formation are being studied and some appear quite feasible.

BRITTON CHANCE JOHN S. LEIGH

\section{Department of Biochemistry and}

Biophysics,

University of Pennsylvania,

Philadelphia, Pennsylvania 19104. USA

ENRICO GRATTON

Laboratory of Fluorescence Dynamics.

University of Illinois,

Urbana-Champaign,

IIIinois 61801, USA

\section{HIV infectivity}

SIR-Bourinbaiar calculates' the amount of p24 gag protein that corresponds to a given number of HIV virions, and discusses how this might be relevant to HIV infectivity in vitro. The gag protein content of a retrovirus was first reported in 1965 to be $5 \times 10^{\text {ln }} \mathrm{g}$ (ref. 2 ),

We suggest, however, that measurements of the total amount of viral protein (p24 or gp120) in HIV cultures or in the plasma of HIV-infected individuals are of very limited value for estimation of the number of infectious particles present. Much of the viral protein secreted from HIV-infected cells is non-particulate, and the proportion of (for example) p24 in virions is a function of the viral genotype and the age of the culture. In extreme cases, less than one per cent of the total p24 and gpI20 present is in virions. Furthermore, many of the intact virions that exist are non-infectious. The calculations made by Bourinbaiar are thus oversimplistic ${ }^{\prime}$

In sera from HIV-infected individuals measurement of p24 content is of even less value for estimation of the number of virions present. Commercial ELISA kits for p24 antigen rely on its capture by antigag antibodies. Binding of the kit antibodies is interfered with by serum anti-gag antibodies to a variable extent dependent on the antibodies in the kit and the individual serum assayed. Absolute quantification of serum $\mathrm{p} 24$, as opposed to its detection, is therefore difficult. Only limited correlations between serum p24 levels and the amount of infectious virus present are found ${ }^{a}$.

Notwithstanding the nonlinear relationship between gag protein content and the number of infectious virions present, we agree on the need for better characterization of parameters influencing HIV infectivity in vitro ${ }^{3}$.

JANE A. MCKEATING JOHN P. MOORE

Chester Beatty Laboratories,

The Institute of Cancer

Research,

237 Fulham Road.

London SW3 6JB, UK

1. Bourinbaiar, A.S. Nature 349, 111 (1991)

Vogt, P.K. Adv Virus Res. 2. $294-385$ (1965)

Mckeating. J.A.. McKnight. A. \& Moore, J.P. J. Virol. 65 $852-860(1991)$

Ho, D.D.. Moudgil. D. \& Alam, M New Engt. J. Med. 321 $1621-1625(1989)$

5. Coombs. R.W. et al. New Engl. J. Med. 321. 1626-1631 (1989)

\section{Scientific Correspondence}

Scientific Correspondence is intended to provide a forum in which readers may raise points of a scientific character. They need not arise out of anything published in Nature. In any case, priority will be given to letters of fewer than 500 words and five references. 